\title{
Relationship between Strategic Leadership \& Cooperative Strategy: The Moderating Role of Clan Culture. (A Case of Small and Medium Sector Organizations of Pakistan)
}

\author{
MUHAMMAD AWAIS EJAZ KHAN \\ PhD Scholar, Faculty of Management Sciences, \\ International Islamic University, Islamabad, Pakistan. \\ Email: m.awais@iiu.edu.pk \\ Tel: +92519019568

\section{Dr. TASNEEM FATIMA} \\ Associate Professor, Faculty of Management Sciences \\ International Islamic University, Islamabad, Pakistan. \\ Email: Tasneem.fatima@iiu.edu.pk \\ Tel: +92519019367
}

\begin{abstract}
Organizational culture has attracted a great interest by theorists and researchers since many years. Leadership in organizations have emphasized on the internal culture strengths and ways to improve the efficiency by incorporating various strategies. Cooperative strategy is being associated with internal strengths and relationship and has been a primary focus area in large organizations with ample opportunity for innovation. Small and medium enterprises however, struggled with innovation and competitiveness. To foster growth, strategic leadership stressed to adopt cooperative strategies and cooperative environment. The current study attempts to reveal the underlying mechanism through which the strategic leadership can improve organizational performance through clan culture and cooperative strategies. Based on the Competing value framework and Resource based view of the firms, This research model was selected and analyzed. Clan culture is used as a moderator variable. The model explores the local Pakistani business leadership strategies in family run businesses as well as small and medium enterprises. Strategic leadership is taken as independent variable while cooperative strategy as dependent variable, Clan culture moderates the relationship between the strategic leadership and cooperative strategies. Resource based view provides a framework to analyze the role of firms tangible and intangible resources to achieve competitive advantage. Data was collected from 294 respondents through survey method. All questionnaires were personally administered. AMOS was used to test the moderated model. The moderated relationship among strategic leadership, clan culture and cooperative strategy resulted significant. Clan culture moderated relationship between Strategic leadership \& cooperative strategy. This study contributes towards the enhanced application of clan culture and cooperative environment in the small and medium sized organizations as well as family owned businesses. To combat competition from larger organizations and substitute products, cooperative strategy can be very effective.
\end{abstract}

Keywords: Strategic Leadership, Organizational Culture, Clan Culture, Cooperative Strategy, SME.

\section{Introduction}

An emerging research on leadership in the mid-1980s was more focused towards strategic leadership rather than focusing managerial versus visionary leadership (Samimi et al., 2020). It focused on how your top leadership positioned their choices and ensures the vitality of the future organization (Mirvis et al., 2010). 
The most successful organizations in terms of their performance are deliberately strategic in leadership planning. These leaders also can align human resources directly to business strategy in an effective manner (House \& Aditya, 1997; Altman \& Tushman, 2017; Alayoubi et al., 2020).

This framework has evolved from numerous arising streams of previous research literature, and it also includes the impact of competing value framework on the relationships of other variables and resourcebased view as well. The CVF has been studied earlier in a mediating role however the clan culture and market culture remain unexplored as moderators. This study is an effort to establish the missing link.

With experience, the ability of leader is transformed into the qualities of the topmost team and the talents of the whole organization (Alayoubi et al., 2020). They can provide vital support to the leader for changes a leader wish to make or put a hurdle for them to make changes possible. For this reason, the best leaders pay close attention to the design of the surrounding elements (Hans, \& Gupta, 2018). Facilitating effective execution and, more importantly, expressing a clear sense of purpose, mixing all the strategies into one coherent strategy, creating effective leadership teams, carefully ranking and sequencing initiatives, and redesigning organizational structures (Torfing et al., 2020). For this reason, strategic leadership design is an integrated group for implementations that creates the capacity for change and the capacity of an organization (Hans, \& Gupta, 2018).

\section{Research Objective}

The objective of this research is to understand the role of clan culture in the context of family- owned businesses which fall mostly in the small and medium enterprise domain. By having a collaborative approach to manage firm will result in the better performance. To understand the moderating role of clan culture between strategic leadership and cooperative strategy, this study will help us analyze and contribute the effectiveness of competing value framework in Pakistani context.

\section{Research Questions}

1. How Strategic leadership will result with outcome of cooperative strategy in small and medium enterprise sector of Pakistan?

2. What impact does clan culture as a moderator have between strategic leadership and cooperative strategy?

\section{Literature Review}

"Understanding strategic leadership reveals what effective leaders are doing to create a strategy-driven organization (Rumsey, 2013; Malik et al., 2020)." Moreover, there is a need to address the crucial resources by strategic leadership that can contribute to enhance the expected success in future. (Hitt and Ireland, 2016) have further discussed and supported this concept, about alignment of strategic leadership with partner organizations "social capital", the ability to create "human capital" is an important resource of firm resource. "(Ireland and Hitt, 2005) stressed on the need of effective strategic leadership capabilities that are vital in the competitive environment of 21st century (Mahdi and Almsafir, 2014)".

\section{Strategic Leadership}

The ability to manage a business, expect, plan, remaining flexible and permit others to foster strategic change, a promising future of the company can be termed as strategic leadership (Kjelin, 2009). Hence the ability of management to continue reinvent the motivations of the sustained presence of the organization. The leader must focus on the operational tasks of the organization while monitoring changes, which affect an organization internally and externally (Ali, B. J., \& Anwar, G. 2021; Malik \& Hadi, 2019). Such changes will determine existence of an organization in the future along with growth prospects. 
Organizational progress is related to the leader (Finkelstein and Hambrick, 2008). Companies fail if the leadership is unable to motivate employees, make them follow his vision, the inability to anticipate threats, not managing the external environment, cannot draw a line between personal and business requirements, being overconfident to manage all issues, dismissing all such staff who differs; and underlying obstacles that happened in the past (Luciano, M. M., Nahrgang, J., \& Shropshire, C. 2020).

Understanding strategic leadership reveals what effective leaders are doing to create a strategy-driven organization (Rumsey, 2013). Moreover, leaders shall stress on vital resources which make future success secure. This point of view is also supported by (Hitt and Ireland, 2016), that strategic leadership has alliances with partners "social capital". "human capital" needs to be transformed into the most important firm resources. (Ireland and Hitt, 2005) stressed the need for strategic leadership effectiveness and enhanced capabilities being expected in the 21 st century's new and competitive environment (Mahdia and Almsafir, 2014).

\section{Cooperative strategy}

(Bell, 2018) have combined strategic and cooperative strategy using resource-based view and game theory with porter's generic strategies to understand the step-by-step impact of decisions on value creation. Cooperative strategy means strategies for both parties to further develop their business relationships, or terminate the relationship, maintain the relationship or enhance the relationship, and these strategies further define the building business relationships. In the supply chain, the cooperative approach has three characteristics (Wei et al., 2019). First, because of different levels and ways of collaboration or trade, cooperation or transaction may be an hour of honor or long term, one that reflects the will to maintain longterm cooperation. Second, the partnership or transaction can be confined to a fixed place or multi-domain that reflects the prospect of deep or multi-place business relationship development. The third party may be processed or processed once, once or repeatedly over a certain period, reflecting the times in which the parties either work together or operate within a specific time period. The three characteristics of the cooperative strategy are linked to the development and transformation of business relationships, but there is still need of study to explore that how strategic leadership can use all these underlying resources for value maximalization of a firm and for gaining competitive advantage.

\section{Clan Culture}

Clan culture is comprised of shared values, combined goals, a community environment with a support system, and emphasizes empowerment, evolution of employees (Di Stefano, G., Scrima, F., \& Parry, E. 2019). Researchers argue that clan culture is a unique organizational culture defined by Wilkins and Ouchi (1983), that can be developed under specific conditions, like relatively prolonged history, maintaining adherence, alternative organizational absence and members' cooperation.

Organizational culture like clan, focus on internal, organic values. Dominated firms by clan culture have a great focus on own maintenance, People flexibility, which includes their customers (Cameron and Quinn, 1999). A friendly working atmosphere is a result of Clan culture, and this belief is that the trust and commitment of the organization directed to the workers help improve communication and employee involvement. Clan culture is classified by cohesion, participation, trust, cooperation, teamwork and the sense of unit (Zhang, C. 2019). Such entities are governed by leaders, who not only invoke loyalty but also tradition. Organizations influenced with more focus on human resource stress clan culture, commitment, and morale. We will take advantage of the RBV to build the argument that how this culture will be useful as a resource to support cooperative strategy to further work for open innovation and competitive advantage. According to RBV clan culture is a powerful internal resource that lies within the organization as it enhances trust and cooperation within mentors and facilitators that positively impact the outcomes 


\section{Strategic leadership and Cooperative strategy in small \& Medium Enterprises}

For the past five decades, researchers in business showed keen interest in the cooperative governance technique. Many nations opened doors for economic expansion, a major shift of manufacturing hub to countries like China and entrepreneurial orientation in SME's (Madanchian, \& Taherdoost, 2019). This great success was attributed to increase in businesses and subsidiaries, fully owned, market-based transactions resulted in cooperative strategy success. The cooperative alignment view as a must, for foreign markets access (Moxon \& Geringer, 1985) has been replaced due to the greater acceptance and trans-border venues as a great opportunity. Any agreement between two or more organizations, contractual or permanent, having mutual tolerance for each other refers to cooperative strategy which directs diversified objectives and goals, with availability of funding, Expert knowledge, technology, executive skills, along with prized assets in control of organization (Anand \& Khanna, 2000; Gulati, 1998). These types of arrangements shall not be permanent; however, they are, such arrangements exist successfully and transform according to new requirements and wish of counterparts (Beamish et al., 2016).

Strategic leaders shall support learning and innovation to achieve vision (Boal and Schultz 2007). Leavy (1996) mention that a lasting vision and objective is the strength of outstanding leaders. In addition, the successful leaders not only visualize opportunities but also possess will to realize the objectives

H1: Strategic Leadership is positively related with cooperative strategy.

\section{Clan culture moderates the relationship of Strategic Leadership and Cooperative Strategy}

We will use the RBV to build the argument on how this culture will be useful as a resource to support the cooperative's strategy to further work for open innovation and competitive advantage. According to RBV clan culture is a powerful internal resource that lies within the organization as it enhances trust and cooperation within mentors and facilitators that positively impacts the outcome, so here clan culture will be used as resource for cooperation strategy and strategic leadership.

H2: Clan culture will moderate the relationship between strategic leadership and cooperative strategy in such a way that the relationship will be stronger when Clan culture will be high.

\section{Theoretical Framework}



\section{Research Methodology}

The data for the study was collected using self-administered questionnaires. Amos was used for anaysis. The sample size was 417 respondents where properly filled and returned questionnaires were 294, assuming $95 \%$ confidence interval with 5\% margin of error. The selected organizations represent the small and medium sector of Pakistan and focused areas were in service, manufacturing organizations. The 
response rate was $70.5 \%$. 90 questionnaires were rejected because of partial responses and 33 questionnaires were not returned at all, resulting in 294 completely filled responses which were recorded for analysis. Cross sectional data was collected using self-administered questionnaires from employees of small and medium enterprise. The employees were selected from the middle and upper-level management positions, who are involved in running the operations, management and are involved in strategic decisionmaking processes. Convenient sampling was adopted for collection of data. Organizations were selected with minimum 150 employees.

The below listed instruments were used for measurement. Ten item scale of strategic leadership by Samson \& Challis (1999) was used. Six items scale by Cameron \& Quinn (1991) was used to measure the clan culture. Cooperative strategy was measured with the help of a five items scale suggested by Wiengarten, et al (2010). The questionnaire was adopted in consideration of the dynamics and requirements of the Pakistani Business environment and culture. Each Item was measured on 7-point Likert scale.

Table 1: Summary of Instruments used

\begin{tabular}{|c|c|c|c|}
\hline Variables & Scale adopted from & No of item & $\alpha$ value \\
\hline Strategic leadership & Samson \& Challis's (1999). & 10 & 0.76 \\
\hline Clan Culture & Cameron and Quinn, 1991 & 06 & 0.86 \\
\hline Cooperative strategy & Fynes et al., 2005 & 05 & 0.925 \\
\hline
\end{tabular}

Moderation was evaluated between DV and IV with AMOS.

\section{Analysis}

Results as per theoretical framework.

\section{Descriptive Statistics}

Table No 2: Sample Description

\begin{tabular}{|l|c|c|c|c|c|}
\hline & $\mathrm{N}$ & Minimum & Maximum & Mean & Std. Deviation \\
\hline Sector & 294 & 1 & 2 & - & .500 \\
\hline Age of the employee & 294 & 1 & 5 & 2.50 & 1.162 \\
\hline Gender of the employee & 294 & 1 & 2 & - & .462 \\
\hline Education of the employee & 294 & 1 & 3 & 2.01 & .387 \\
\hline Experience of the employee & 294 & 1 & 4 & 2.33 & 1.044 \\
\hline $\begin{array}{l}\text { Designation in the current } \\
\text { organization }\end{array}$ & 294 & 1 & 3 & - & .746 \\
\hline Valid N (listwise) & 294 & & & & \\
\hline
\end{tabular}

\section{Sample Description}

Out of 417 sample, $75 \%$ respondents were male while female respondents comprised of $25 \%$. Respondents had varied qualification levels, Ph.D. being the highest qualification; $88 \%$ held master's degree where as 11 $\%$ had either 18 years of qualifications and $1 \%$ were Ph.D. 66\% respondents belonged to the age bracket $24-40$, and $24 \%$ belonged to the $41-50$ age group, while $10 \%$ were from 50 to 59 years group. Almost $53 \%$ respondents had 15 years or more job experience, $39 \%$ had 20 years experiences while $8 \%$ of the sample population had over 25 years of experience including senior management roles. The sample population comprised of 15 organizations from various fields and domains in private and government sector. It was ensured that the sample reflects senior and middle management roles so the results can be generalized. 


\section{Moderation Results}

Table No 3: Moderation Analysis Results-CC (Bootstrap 95\% Confidence Interval) Cooperative Strategy (CS)

\begin{tabular}{|lllllc|}
\hline & $\mathbf{B}$ & SE & P & LLCI & ULCI \\
\hline Constant & 5.2354 & .0473 & .0000 & 5.1422 & 5.3286 \\
SL & .0632 & .0787 & .4226 & -.0917 & .2181 \\
CC & .5696 & .0631 & .0000 & .4454 & .6938 \\
SL x CC & .1740 & .0632 & .0063 & .0496 & .2948 \\
$\Delta$ R2 due to Interaction & .0148 & \multicolumn{5}{c}{ Slope Test } \\
\hline \multicolumn{7}{c}{} \\
\hline Moderator: CC & -.0930 & .1142 & .4160 & -.3178 & .1317 \\
-.8977 & .0632 & .0787 & .4226 & -.0917 & .2181 \\
.0000 & .2194 & .0761 & .0042 & .0697 & .3691 \\
.8977 & & & & \\
\hline
\end{tabular}

\section{Moderating role of Clan Culture (CC) between Strategic Leadership and Cooperative Strategy}

Hypothesis 2 proposes that Clan Culture $(\mathbf{C C})$ moderates the relationship between Strategic leadership and Cooperative strategy. i.e., $\beta=.17, p<.01 ; \Delta R^{2}=.014, p<.01$. Simple slope test further confirmed the slope significance i.e., relationship between Strategic leadership and Cooperative strategy was stronger at higher level of the moderator, i.e., CC. Resultantly, (H2) proves significant. The Interaction plot further describes the strong relationship between cooperative strategy and strategic leadership. Under higher clan culture the relationship will be further strengthened between the two.

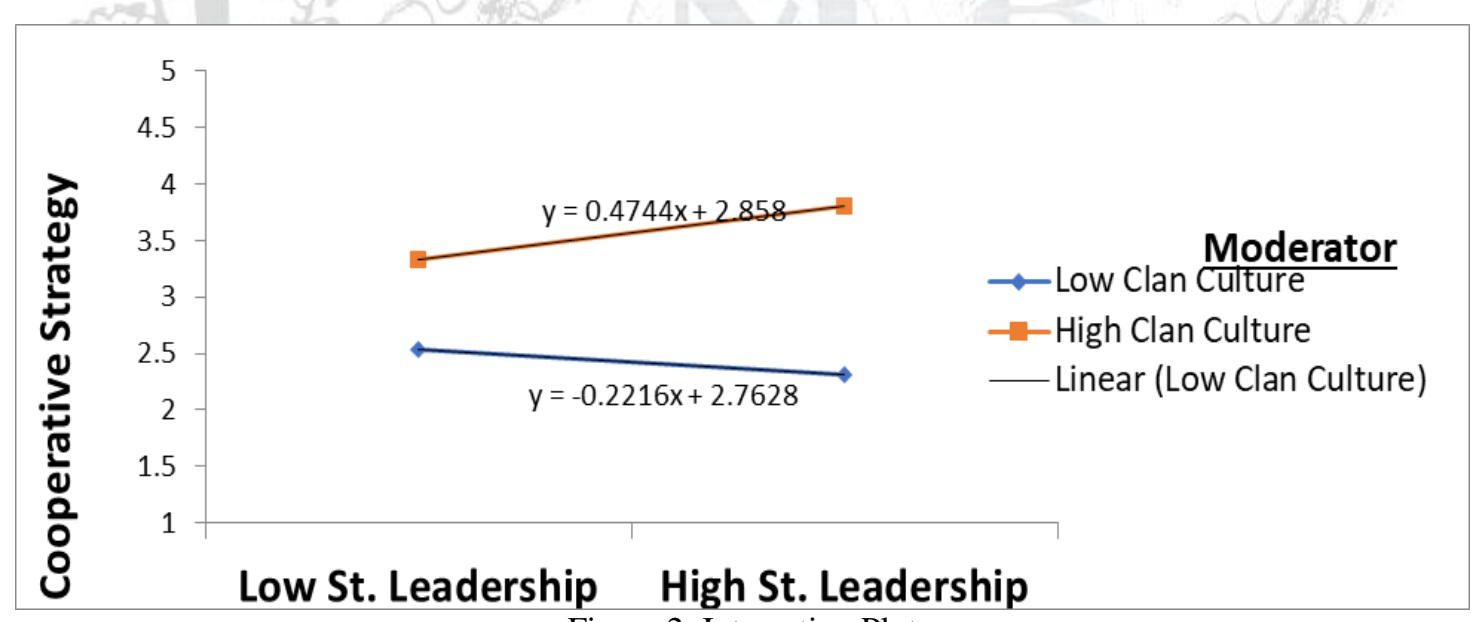

Figure 2: Interaction Plot

\section{Hypotheses Testing}

\section{Sample Description}

With a series of test conducted to test the hypotheses, statistical results were obtained. Significant relationship between the independent and dependent variable was observed $(\mathrm{Sig}=.000)$. A positive relationship existed between strategic leadership and cooperative strategy with $(\beta=.52)$. 
Table No 4: ANOVA $^{\mathrm{a}}$

\begin{tabular}{|ll|c|c|c|c|c|}
\hline \multirow{2}{*}{ Model } & & Sum of Squares & df & Mean Square & F & Sig. \\
\hline 1 & Regression & 55.776 & 1 & 55.776 & 108.986 & $.000^{\mathrm{b}}$ \\
\cline { 2 - 7 } & Residual & 149.950 & 293 & .512 & & \\
\cline { 2 - 7 } & Total & 205.726 & 294 & & & \\
\hline
\end{tabular}

a. Dependent Variable: CS

b. Predictors: (Constant), Strategic Leadership

Table No 5: Coefficient

\begin{tabular}{|ll|c|c|c|c|c|}
\hline Model & & $\begin{array}{c}\text { Unstandardized } \\
\text { Coefficients } \\
\text { B }\end{array}$ & Std. Error & $\begin{array}{c}\text { Standardized } \\
\text { Coefficients } \\
\text { Beta }\end{array}$ & $\mathrm{t}$ & Sig. \\
\hline 1 & & 2.257 & .296 & & 7.621 & .000 \\
\cline { 2 - 7 } & $\begin{array}{l}\text { (Constant) } \\
\text { Strategic } \\
\text { Leadership }\end{array}$ & .593 & .057 & .521 & 10.440 & .000 \\
\hline
\end{tabular}

a. Dependent Variable: Cooperative Strategy

\section{Discussion}

Though past research has focused and analyzed the antecedents and consequences of strategic leadership thoroughly, nevertheless, the way strategic leadership affects cooperative strategy outcome directly along with the interactive effects of clan culture was unexplored yet. Especially in a single model and in the context of Pakistan. This may be the first exploratory study conducted in Pakistan.

Overall, both hypotheses were accepted and found significant. The results supported the hypotheses. Strategic leadership showed positive relationship to the dependent variable Hypothesis 1 (cooperative strategy). Process macro resulted in full support of the given hypotheses. Preacher's and Hayes process revealed a strong impact of Strategic leadership on cooperative strategy. It determines that strategic leadership promotes cooperative strategy in organizations.

Hypothesis 2, states that clan culture moderates the relationship between strategic leadership and cooperative strategy. The moderating effect of clan culture between the proposed relationship, analyzed with Hayes Process. Process macro revealed and displayed support for the relationship that clan culture moderates the relationship between strategic leadership and cooperative strategy as interaction term (strategic leadership $\mathrm{x}$ clan culture) resulted significant i.e., $\beta=.17, \mathrm{p}<.01 ; \Delta \mathrm{R}^{2}=.014, \mathrm{p}<.01$.

This study is contributory from a strategic point of view as it includes both managers and supervisors and top managements point of view. This entails the crucial insights as how strategic leadership, promotes cooperative strategy, which positively affects the organizational climate. As employees are termed as the vital and valued resource of an organization, pairing up with leadership will strengthen innovation, job satisfaction, and employee engagement, hence improving commitment at all levels.

\section{Conclusion}

The existing literature shows evidence that the moderating role of culture in the strategy literature is still to be explored and it requires a better understanding in different cultural context and business settings. Researchers argued that the existing strategic literature needs further elaboration. Strategic leadership needs to be viewed as a driving force to apply CVF and RBV to analyze the impact on the strategies in strategic organizational literature. The current study is an effort to expand the effort to address strategic leadership and its impact in fostering cooperative strategy. In addition, in past several researchers have undertaken the 
research to study interactive effects of organizational moderators and their impact on strategic leadership and work outcomes. As recommended by (Kurzhals et al, 2020), this study endeavored to examine clan culture interactive effects on strategic leadership and its impact on firms' cooperative strategy. The results however supported the hypotheses and supported the model accuracy.

\section{Limitations and Future Research Directions}

Just as other studies have limitations, this study also is bound in ways. At first, the sample represents the respondents of the twin cities of (Islamabad and Rawalpindi), as many of the respondents were employed in government organizations. Resultantly the finding of the study may not be generalized country wide due to culture, share of private organizations in other manufacturing cities. Secondly, due to the nature of study the data was collected in 3 tiers where IV and Moderating variable were measured at $\mathrm{t} 1$ and $\mathrm{t} 2$, and DV was analyzed at $\mathrm{t} 3$. These do not reflect a fulltime lagged design study. As a result, the future research shall be broader and by observing a complete time lag design. In addition, the relationship shall be tested with innovation and competitive strategy to further support the role of clan culture as a moderator at varied time intervals. Moreover, Prospective researchers are also encouraged to explore market, adhocracy and hierarchy culture-based relations in the hypothesized model of current research.

\section{Practical Implications}

From the results of the study, it can be derived that having a collaborative culture in the organization by eliminating rigid hierarchies, enhanced communication and trust will result in better organization performance. Especially in family-owned small organizations, involvement of employees at all levels will further strengthen the relationship with leaders and enhance productivity.

\section{References}

Ali, B. J., \& Anwar, G. (2021). Business strategy: The influence of Strategic Competitiveness on competitive advantage. International Journal of Electrical, Electronics and Computers, 6(2).

Alayoubi, M. M., Al Shobaki, M. J., \& Abu-Naser, S. S. (2020). Strategic leadership practices and their relationship to improving the quality of educational service in Palestinian Universities. International Journal of Business Marketing and Management (IJBMM), 5(3), 11-26.

Anand, B. N., \& Khanna, T. (2000). Do firms learn to create value? The case of alliances. Strategic management journal, 21(3), 295-315.

Au, A. K. M., Altman, Y., \& Roussel, J. (2008). Employee training needs and perceived value of training in the Pearl River Delta of China: A human capital development approach. Journal of European Industrial Training.

Barney, J. (1991). Firm resources and sustained competitive advantage. Journal of management, 17(1), 99120.

Beamish, P. W., \& Lupton, N. C. (2016). Cooperative strategies in international business and management: Reflections on the past 50 years and future directions. Journal of World Business, 51(1), 163-175.

Bel, R. (2018). A property rights theory of competitive advantage. Strategic Management Journal, 39(6), 1678-1703.

Boal, K. B., \& Hooijberg, R. (2000). Strategic leadership research: Moving on. The Leadership Quarterly, 11(4), 515-549.

Cameron, K. S., Quinn, R. E., Degraff, J., \& Thakor, A. V. (2006). Creating values leadership. Creating value in organizations.

Child, J., Faulkner, D., Tallman, S., \& Tallman, S. B. (2005). Cooperative strategy. Oxford University Press, USA.

Di Stefano, G., Scrima, F., \& Parry, E. (2019). The effect of organizational culture on deviant behaviors in the workplace. The International Journal of Human Resource Management, 30(17), 2482-2503. 
Finkelstein, S., Hambrick, D., \& Cannella, A. A. (1996). Strategic leadership. St. Paul: West Educational Publishing.

Kjelin, E. (2009). A concept analysis for strategic leadership. EBS Review, (26).

Gulati, R. (1998). Alliances and networks. Strategic management journal, 19(4), 293-317.

Halawi, L. A., Aronson, J. E., \& McCarthy, R. V. (2005). Resource-based view of knowledge management for competitive advantage. The electronic journal of knowledge management, 3(2), 75.

Hans, S., \& Gupta, R. (2018). Job characteristics affect shared leadership: The moderating effect of psychological safety and perceived self-efficacy. Leadership \& Organization Development Journal.

Hitt, M. A., Ireland, R. D., \& Hoskisson, R. E. (2016). Strategic management: Concepts and cases: Competitiveness and globalization. Cengage Learning.

House, R. J., \& Aditya, R. N. (1997). The social scientific study of leadership: Quo vadis?. Journal of management, 23(3), 409-473.

Kurzhals, C., Graf-Vlachy, L., \& König, A. (2020). Strategic leadership and technological innovation: A comprehensive review and research agenda. Corporate Governance: An International Review, 28(6), 437-464.

Leavy, B. (1996). On studying leadership in the strategy field. The Leadership Quarterly, 7(4), 435-454.

Luciano, M. M., Nahrgang, J. D., \& Shropshire, C. (2020). Strategic leadership systems: Viewing top management teams and boards of directors from a multiteam systems perspective. Academy of Management Review, 45(3), 675-701.

Madanchian, M., \& Taherdoost, H. (2019). Assessment of leadership effectiveness dimensions in small \& medium enterprises (SMEs). Procedia Manufacturing, 32, 1035-1042.

Mahdi, O. R., \& Almsafir, M. K. (2014). The role of strategic leadership in building sustainable competitive advantage in the academic environment. Procedia-Social and Behavioral Sciences, 129, 289-296.

Malik, I. A., \& Hadi, N. U. (2019). Inspirational factors of electronic word of mouth: A case of social networking sites. Journal of Managerial Sciences, 13(2), 253-254.

Malik, I. A. Apprehending Inspirational Persuasion Factors for Intention to use eWOM by Highlighting Mediation of Attitude towards eWOM: A Case of Social Network Sites.

Moxon, R. W., \& Geringer, J. M. (1985). Multinational ventures in the commercial aircraft industry. Columbia Journal of World Business, 20(2), 55-62.

Quinn, R. E., \& Rohrbaugh, J. (1981). A competing values approach to organizational effectiveness. Public productivity review, 122-140.

Rumsey, M. G. (2013). The elusive science of leadership. In The Oxford handbook of leadership (p. 455). Oxford University Press.

Samson, D., \& Challis, D. (1999). Patterns of excellence: The new principles of corporate success. Financial Times Management.

Samimi, M., Cortes, A. F., Anderson, M. H., \& Herrmann, P. (2020). What is strategic leadership? Developing a framework for future research. The Leadership Quarterly, 101353.

Torfing, J., Cristofoli, D., Gloor, P. A., Meijer, A. J., \& Trivellato, B. (2020). Taming the snake in paradise: combining institutional design and leadership to enhance collaborative innovation. Policy and Society, 39(4), 592-616.

Wei, S., Zhang, Z., Ke, G. Y., \& Chen, X. (2019). The more cooperation, the better? Optimizing enterprise cooperative strategy in collaborative innovation networks. Physica A: Statistical Mechanics and its Applications, 534, 120810.

Wiengarten, F., Humphreys, P., Cao, G., Fynes, B., \& McKittrick, A. (2010). Collaborative supply chain practices and performance: exploring the key role of information quality. Supply Chain Management: An International Journal.

Wilkins, A. L., \& Ouchi, W. G. (1983). Efficient cultures: Exploring the relationship between culture and organizational performance. Administrative science quarterly, 468-481. 